\section{About the Spencer and Graham Article}

\section{Victor Pambuccian}

7 $\mathrm{n}$ "The Elementary Proof of the Prime Number Theorem" by Joel Spencer and Ronald Graham (The Mathematical Intelligencer Vol. 31 (2009), No. 3, pp. 18-23), Ernst Straus is quoted as follows: "The elementary proof has so far not produced the exciting innovations in number theory that many of us expected to follow."

But it was the essential step in reassigning this theorem to the realm of pure arithmetic from that of real or complex analysis, in line with Hilbert's concern for the purity of the method: "In der modernen Mathematik [wird] solche Kritik sehr häufig geübt, woher das Bestreben ist, die Reinheit der Methode zu wahren, d. h. beim Beweise eines Satzes womöglich nur solche Hilfsmittel zu benutzen, die durch den Inhalt des Satzes nahe gelegt sind (1898-1899)." (In modern mathematics one often applies such a critique, the objective being to preserve the purity of the method, i.e., to use in the proof of a theorem only those means that are suggested by its content).

Specifically, the logarithm function showing up in the Prime Number Theorem can be replaced by a function definable entirely inside number theory, and the resulting theorem can be proved in a fragment of first-order Peano Arithmetic ( $I \Delta_{0}+$ exp, to be precise), as shown in Cornaros and Dimitracopoulos (1994), "The prime number theorem and fragments of PA."

\section{REFERENCES}

Cornaros C. and C. Dimitracopoulos. The prime number theorem and fragments of PA. Arch. Math. Logic 33(4), 1994, 265-281.

Spencer J. and Ronald Graham, The elementary proof of the Prime Number Theorem, Math. Intelligencer 31(3), 2009, 18-23, DOI: 10.1007/s00283-009-9063-9.

Division of Mathematical and Natural Sciences Arizona State University-West Campus

Phoenix, AZ 85069-7100

USA

e-mail: victor.pambuccian@asu.edu 